\title{
Vertical Long Axis of the Heart
}

National Cancer Institute

\section{Source}

National Cancer Institute. Vertical Long Axis of the Heart. NCI Thesaurus. Code $C 95015$.

An oblique plane through the heart containing its long axis and showing 2 chambers. Also any plane parallel to this can be called a vertical long axis view. 